\title{
Note
}

\section{Capacité de rétention d'eau des protéines laitières}

\author{
G. Blond et I. Montupet
}

ENSBANA, Laboratoires de biologie physico-chimique et de biochimie alimentaire, 21000 Dijon, France

(reçu le 3-2-1988, accepté le 28-9-1988)

\section{Introduction}

Les propriétés fonctionnelles essentielles à l'emploi des protéines laitières comme additifs technologiques sont liées à leurs possibilités d'interactions avec l'eau et plus particulièrement à leur pouvoir de rétention de l'eau.

Les protéines laitières sont effectivement ajoutées à des viandes hachées pour augmenter leurs propriétés de rétention d'eau, stabiliser leurs émulsions et améliorer leurs caractéristiques de texture et de jutosité. De même, leur addition dans des produits de boulangerie assure au produit fini une texture plus moelleuse.

La terminologie anglo-saxonne utilise, pour caractériser cette propriété, l'expression : water holding capacity (WHC); nous la définirons comme la "capacité de rétention d'eau" (CRE). Cet indice de fonctionnalité est mesuré, en général, en exerçant une force externe sur le produit hydraté : pression, ou le plus souvent centrifugation. Les conditions de mesure dépendent du choix des expérimentateurs ou de l'échantillon à évaluer. II n'y a aucune normalisation dans ce type de mesure.

Son usage est plus répandu pour les matériaux structurés : viande (Hamm,
1972), gels protéiques (Hermansson et Luciano, 1982). Cependant Quinn et Paton (1979) proposent, pour des poudres protéiques, une méthode basée sur la centrifugation d'une pâte, mais elle n'est utilisable qu'avec des produits insolubles; Knightbridge et Goldman (1975) mesurent à l'aide d'un farinographe une capacité d'absorption d'eau par des poudres de protéines laitières, l'addition de farine permettant d'avoir une pâte suffisamment consistante.

L'évaluation de cette propriété de rétention d'eau n'est pas possible avec les méthodes déjà décrites pour les produits laitiers hydratés; aussi, nous en proposons une, dérivée de celle mise au point par Thompson et al. (1969) pour mesurer la voluminosité des micelles. Cette méthode est utilisable pour les liquides comme pour les poudres; les résultats obtenus montrent les informations que l'on peut en attendre, mais aussi ses limites.

\section{Matériel et Méthodes}

\section{Echantillons}

Les produits testés sont soit des fractions laitières préparées au laboratoire, natives ou 
modifiées chimiquement, puis déshydratées par lyophilisation, soit des produits d'origine industrielle auxquels nous donnerons simplement des noms de code :

- lactosérums industriels déshydratés : LsA, LsB;

- caséine isoélectrique obtenue au laboratoire, par précipitation isoélectrique à $\mathrm{pH} 4,6$;

- caséinate de sodium obtenu par neutralisation à $\mathrm{pH} 6,8$ de la caséine isoélectrique par de la soude;

- caséinate de sodium galactosylé chimiquement selon la méthode de Lee et al. (1979), taux de glycosylation $80 \%$;

- caséinate de sodium et caséinate de calcium industriels de même origine congelés ou déshydratés par atomisation;

- caséinate haute viscosité (produit industriel).
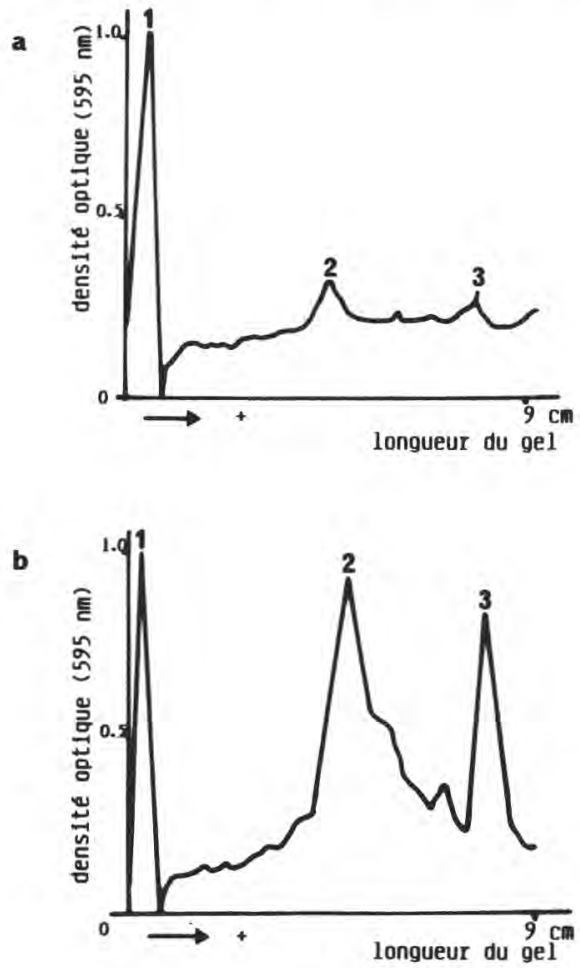

Fig. 1. Densitogramme des concentrés protéiques des lactosérums. a. LsA (solubilité $6 \%$ ). b. LsB (solubilité 70\%). Gel vertical, méthode de Maurer (1981). 1. Dépôt (25 $\mu \mathrm{l}$ à $1 \%$ de protéines). 2 . B-lactoglobuline ou dérivé.

\section{Solubilité des poudres de lactosérums}

La solubilité des lactosérums est évaluée par le pourcentage d'azote soluble, dosé par la méthode de Kjeldahl, d'une solution à $1 \%$ de protéines à $\mathrm{pH} 7$, centrifugée $20 \mathrm{~min}$ à $4000 \mathrm{~g}$.

\section{Mesure de la capacité de rétention d'eau}

Les concentrations des solutions protéiques analysées sont standardisées à $2,5 \%(\mathrm{~g} / \mathrm{g})$; si la protéine est déshydratée, elle est dissoute dans l'eau distillée; le $\mathrm{pH}$ des solutions est ajusté à 7,1 . Pour les caséinates, il est ajouté $0,03 \mathrm{M} \mathrm{CaCl}_{2}$ dans le milieu.

Les solutions protéiques sont centrifugées à $65000 \mathrm{~g}$ pendant $1 \mathrm{~h} 30$ à $20^{\circ} \mathrm{C}$ (ultracentrifugeuse Beckman L855M rotor SW41 T1). Après centrifugation, les tubes (polyallomer $14 \times 89$ $\mathrm{mm}$ ) sont égouttés pendant $5 \mathrm{~min}$ et coupés au-dessus du culot de centrifugation. Celui-ci est lyophilisé, afin de déterminer avec précision sa teneur en eau. La capacité de rétention d'eau (CRE) est exprimée en gramme d'eau par gramme de matière sèche.

\section{Résultats et Discussion}

\section{Lactosérums}

L'étude n'a porté que sur 2 poudres de lactosérums industriels dont les caractéristiques techniques sont très différentes bien que toutes deux soient issues de lactosérum doux. Le premier, que nous avons codé LsA, est un concentré à haute pureté protéique $(70 \%)$, mais très dénaturé (cf. électrophorèse) et qui a de ce fait une solubilité réduite à $6 \%$.

Le second, LsB, moins riche en protéines $(14 \%)$, est beaucoup moins dénaturé par les traitements de préparation; sa solubilité est encore de $70 \%$. On notera que la capacité d'hydratation évaluée par la méthode de Thompson est beaucoup plus élevée pour le produit le moins dénaturé (Tableau I). 
Cela est tout à fait en accord avec les mesures effectuées par Short (1980); les capacités d'absorption d'eau qu'il mesure au farinographe sur des poudres de lactosérums précipités par thermocoagulation et séchés varient de $70 \mathrm{~g}$ d'eau / $100 \mathrm{~g}$ de poudre à $147 \mathrm{~g}$ d'eau / $100 \mathrm{~g}$ de poudre pour le produit le moins dénaturé; la CRE mesurée pour le lactosérum LsA est du même ordre de grandeur.

\section{Caséines et caséinates}

Si la méthode s'est révélée sans problème pour évaluer la CRE de la caséine isoélectrique, il n'en a pas été de même pour les caséinates qui sont solubles. Pour pouvoir former avec les caséinates des agrégats sédimentables par centrifugation sans provoquer une «insolubilisation", nous avons ajouté des ions $\mathrm{Ca}^{++}$au milieu en quantité équivalente à celle du lait $\left(0,03 \mathrm{M} \mathrm{CaCl}_{2}\right)$. II se forme alors des analogues de micelles (associations calciques mal définies) dont on peut évaluer la capacité de rétention d'eau par la méthode de Thompson.

L'ensemble des résultats obtenus, et reportés sur le Tableau I, montre que :

- la capacité de rétention d'eau varie beaucoup aussi bien d'un produit à l'autre que pour un même type de produit: si nous considérons les caséinates de sodium testés, leur CRE dépend et de leur origine et de leur mode de préparation;

- pour les produits de même origine (ici les caséinates industriels), la capacité d'hydratation d'un caséinate de sodium est supérieure à celle d'un caséinate de calcium. Cela confirme aussi bien les résultats obtenus par Knightbridge et Goldman (1975) avec un farinographe, que ceux obtenus par Ruegg et Moor (1984) par sorption d'eau sur des produits pulvérulents;

Tableau I. Mesure de la capacité de rétention d'eau de quelques produits laitiers.

Produit
Capacité de rétention d'eau

( $g$ d'eau / $g$ mat. sèche)

$(n-s) \mathrm{pH}=7,1$

\begin{tabular}{ll}
\hline Sans addition & Avec addition \\
de $\mathrm{CaCl}_{2}$ & de $\mathrm{CaCl}_{2}(0,03 \mathrm{M})$
\end{tabular}

Lactosérum LsA
Lactosérum LsB
Caséine isoélectrique
Caséinate de $\mathrm{Na}$
Caséinate de $\mathrm{Ca}$ industriel
$\quad$ - congelé
- séché
Caséinate de $\mathrm{Na}$ industriel
— congelé
- séché
Caséinate haute viscosité
Caséinate galactosylé (80\%)

$\begin{array}{ll}1,4 \quad(9-0,05) & \\ 3,2 \quad(9-0,09) & \\ 1,21 \quad(9-0,002) & 2,55(9-0,02) \\ \begin{array}{l}\text { non mesurable } \\ \text { non mesurable }\end{array} & 2,97(6-0,22) \\ & 2,09(6-0,19) \\ \text { non mesurable } & 4,10(6-0,29) \\ & 3,25(6-0,22) \\ & 4,37(9-0,04) \\ \text { non mesurable } & 4,44(9-0,09) \\ \text { non mesurable } & \end{array}$


- la fixation d'un groupement fonctionnel comme un glucide augmente la CRE de la protéine; parallèlement, Courthaudon et al. (1988) ont mesuré un accroissement de sa solubilité aussi bien à $\mathrm{pH} 1$ qu'à $\mathrm{pH} 7$;

- il existe une influence négative du séchage (ici par atomisation) sur l'hydratation des protéines.

La méthode d'étude des propriétés d'hydratation des protéines laitières que nous proposons permet d'obtenir des résultats pratiques intéressants, tout à fait comparables à ceux observés avec d'autres techniques. Elle met particulièrement en évidence le fait qu'une capacité d'hydratation est d'autant plus importante que le produit est plus soluble. Bien sûr, c'est une méthode globale qui ne permet pas de distinguer la part qui revient à la fraction protéique de celle qui dépend des sels ou des sucres présents dans le milieu, et des structures qui en résultent; mais, dans la pratique industrielle, on utilise toujours des produits complexes. Son principal avantage est qu'elle rend possible l'étude des produits ayant subi des traitements technologiques différents sans nécessiter de préparations complémentaires (concentration, déshydratation), susceptibles elles aussi d'entraîner une modification supplémentaire de leur capacité d'hydratation. C'est donc une méthode utilisable pour évaluer les modifications créées par des techniques suffisamment maîtrisées pour ne pas insolubiliser le matériau mais qui peuvent néanmoins diminuer sa fonctionnalité.

\section{Références}

Courthaudon J.L., Colas B. \& Lorient D. (1989) Covalent binding of glycosyl residues to bovine caseins : effects on solubility. J. Agric. Food Chem. 37, 32-36

Hamm R. (1972) Kolloid-Chemie des Fleisches. Verlag Paul Pasey, Berlin

Hermansson A.M. \& Luciano M.L. (1982) Gel characteristics. Water binding properties of blood plasma gels and methodological aspects on the water-binding of gel systems. J. Food Sci. 47, 1955-1959

Knightbridge J.P. \& Goldman A. (1975) Water absorptive capacity of dried milk products. N.Z.J. Dairy Sci. Technol. 10, 152-157

Lee H.S., Sen L.C., Clifford A.J., Whitaker J.R. \& Feeney R.E. (1979) Preparation and nutritional properties of caseins covalently modified with sugars. Reductive alkylation of lysines with glucose, fructose or lactose. J. Agric. Food Chem. 27, 1094-1098

Maurer H.R. (1981) Disc Electrophoresis. Gruyter Ed., Berlin

Quinn J.R. \& Paton D. (1979) A practical measurement of water hydration capacity of protein material. Cereal Chem. 56, 38-40

Ruegg M. \& Moor U. (1984) Effects of calcium on the hydration of casein. 1-Water sorption and fine structure of calcium caseinates compared with sodium caseinates in the $\mathrm{pH}$ range 4,6-8. J. Dairy Res. 51, 103-111

Short J.L. (1980) The water absorption capacity of heat precipitated whey proteins. N.Z.J. Dairy Sci. Technol. 15, 167-176

Thompson H.P., Boswell R.T. \& Martin V. (1969) Casein pellets : solvation and heat stability of individual cow's milk. J. Dairy Sci. 52, 796-798 